\title{
вмJ Global Health Community-orientated primary care: a scoping review of different models, and their effectiveness and feasibility in sub-Saharan Africa
}

\author{
Bob Mash, ${ }^{1}$ Sunanda Ray, ${ }^{2}$ Akye Essuman, ${ }^{3}$ Edu Burgueño ${ }^{4}$
}

To cite: Mash B, Ray S, Essuman A, et al. Communityorientated primary care: a scoping review of different models, and their effectiveness and feasibility in sub-Saharan Africa. BMJ Global Health 2019:4:e001489. doi:10.1136/ bmjgh-2019-001489

Handling editor Valery Ridde

Received 16 February 2019 Revised 10 June 2019 Accepted 10 June 2019

\section{Check for updates}

(c) Author(s) (or their employer(s)) 2019. Re-use permitted under CC BY-NC. No commercial re-use. See rights and permissions. Published by BMJ.

${ }^{1}$ Department of Family and Emergency Medicine, Stellenbosch University, Cape Town, South Africa

${ }^{2}$ Department of Community Health, University of Zimbabwe College of Health Sciences, Harare, Zimbabwe

${ }^{3}$ Department of Community Health, University of Ghana, Accra, Ghana

${ }^{4}$ Department of Family Medicine Université de Mwene-Ditu,

Mwene-Ditu, Congo (the

Democratic Republic of the Congo)

Correspondence to Professor Bob Mash; rm@sun.ac.za

\section{ABSTRACT}

Introduction Community-orientated primary care (COPC) is an approach to primary healthcare $(\mathrm{PHC})$ that originated in South Africa and contributed to the formulation of the Declaration of Alma-Ata 40 years ago. Despite this, PHC remains poorly developed in sub-Saharan African countries. There has been a resurgence of interest in strengthening PHC systems in the last few years and identifying key knowledge gaps. COPC has been an effective strategy elsewhere, most notably Brazil. This scoping review investigated COPC in the sub-Saharan African context and looked for evidence of different models, effectiveness and feasibility.

Methods Databases were systematically searched using a comprehensive search strategy to identify studies from the last 10 years. A methodological guideline for conducting scoping reviews was followed. A standardised template was used to extract data and compare study characteristics and findings. Studies were grouped into five categories: historical analysis, models, implementation, educational studies and effectiveness.

Results A total of 1997 publications were identified and 39 included in the review. Most publications were from the last 5 years $(n=32)$, research $(n=27)$, from South Africa $(n=27)$, focused on implementation $(n=25)$ and involving case studies $(n=9)$, programme evaluation $(n=$ 6) or qualitative methods $(n=10)$. Nine principles of COPC were identified from different models. Factors related to the implementation of COPC were identified in terms of governance, finances, community health workers, primary care facilities, community participation, health information and training. There was very little evidence of effectiveness of COPC.

Conclusions There is a need for further research to describe models of COPC in Africa, investigate the appropriate skills mix to integrate public health and primary care in these models, evaluate the effectiveness of COPC and whether it is included in training of healthcare workers and government policy.

\section{INTRODUCTION}

Forty years ago, the Declaration of Alma-Ata was the first international declaration that emphasised the importance of primary
Summary box

What is already known?

- Community-orientated primary care (COPC) is an approach to delivering primary healthcare (PHC) that integrates primary care practice and public health for a defined community.

What are the new findings?

- African studies agree on nine key principles for implementing COPC.

- African studies identify factors related to governance, finances, community health workers, primary care facilities, community participation, health information and training that influence the implementation of COPC.

What do the new findings imply?

- There is a need to evaluate the extent to which COPC is supported by health policy in Africa and incorporated into the training of healthcare workers.

- There is a need to move from studying implementation to evaluating the effectiveness of COPC in strengthening PHC and enabling universal health coverage.

healthcare (PHC) ${ }^{1}$ One of the antecedents of this declaration was a small community project at Pholela in rural South Africa. ${ }^{2}$ This project was a small-scale, practical and effective manifestation of many of the principles that were later enshrined in the declaration. The approach to PHC that was developed at Pholela became known as community-orientated primary care (COPC). COPC is 'a continuous process by which primary healthcare is provided to a defined community on the basis of its assessed health needs, by the planned integration of primary care practice and public health'.

Despite the aspirations for PHC expressed in the Alma-Ata declaration and the emergence of COPC in South Africa, PHC systems in many African countries are under-resourced 
and in need of strengthening. The African continent has $25 \%$ of the global disease burden, but only $3 \%$ of the world's health workers and less than $1 \%$ of the world's health expenditure. ${ }^{4}$ PHC in Africa has suffered from a lack of government commitment and investment, fragmentation by vertical disease-specific programmes, catastrophic out-of-pocket payments, low level healthcare workers with limited training, poor infrastructure, a lack of supportive supervision and low status within the health system. ${ }^{5}$

The importance of PHC for strengthening health systems was reiterated in the 2008 World Health Report. ${ }^{6}$ The forty-year commemoration of Alma-Ata in 2018 has also led to updated models of $\mathrm{PHC}^{7}$ and a new intergovernmental declaration. ${ }^{8}$ The need to strengthen PHC as a system and not just care for specific diseases has gained momentum and the global Primary Healthcare Performance Initiative (PHCPI) has recently articulated a new framework to evaluate PHC. ${ }^{9}$ This has led to the establishment of a research consortium to address priority research questions related to the framework and PHC as a system. This scoping review was part of an African process to assess the evidence base and identify key knowledge gaps.

From South Africa, the COPC approach was adopted internationally with examples in the USA, UK and Israel. ${ }^{10}$ A systematic review completed in 2008 found that 'most publications related to COPC do not use the complete COPC model as originally described and evidence for its effectiveness is lacking'. ${ }^{10}$ This review, however, required publications to specifically mention COPC. Many approaches to implementing PHC have emphasised community orientation without using the term COPC, such as in Bolivia and Brazil. ${ }^{11}{ }^{12}$ Brazil's family healthcare teams are one such prominent example at scale that has made a significant impact on child health indicators. ${ }^{12}$ COPC in the African context is most likely to involve community health workers (CHW) as in the Brazilian model. There is evidence for the benefit of CHW programmes in Africa although not always within a COPC model. ${ }^{13}$ Most recently the South Africa government has committed to COPC as part of health reforms designed to pave the way for national health insurance. ${ }^{14}$

The aim of this scoping review, therefore, was to assess the evidence for COPC in the African context over the last 10 years since the previous systematic review. The review may guide current attempts at strengthening PHC as well as identify important knowledge gaps that should be addressed through future research.

\section{METHODS}

A scoping review ${ }^{15}$ was conducted on different COPC models, their effectiveness and feasibility using the following questions:

- What are the different ways in which COPC has been implemented in Africa?
- What is known about the strengths and weaknesses of current approaches to COPC in Africa?

- What evidence exists for the effectiveness of COPC in Africa?

\section{Inclusion and exclusion criteria}

Articles needed to either explicitly refer to COPC or the project being evaluated should include at least four of the five key principles from the definition ${ }^{3}$ :

- Be located within a PHC context

- Focus on a defined community

- Include an assessment of the health needs of the community

- Integrate primary care practice and public health

- Be planned as a continuous process

Studies were included if they were about humans, in English or French and in the last 10 years (up to and including 2017). No limits were placed on the type of article. The application of these criteria meant that a large amount of the literature on CHWs was excluded from the review as studies would often evaluate a specific competency or health programme and not COPC.

\section{Search strategy}

The following search terms were used to search for the evidence:

- ['Community-orientated primary care' OR 'Community-orientated primary care' $\mathrm{OR}$ 'COPC'] AND Africa

- Community health workers $(\mathrm{mh}) /$ organisation \& administration (OG) AND Africa

- Community participation (mh) AND primary healthcare (mh) AND Africa

- Community health services $(\mathrm{mh}) /$ organisation \& administration (OG) AND primary healthcare (mh) AND Africa (mh)

Searches were conducted in the following databases: Cochrane Library, Trip, PubMed, Google Scholar, Sabinet, Africa Wide Information and African Journals on Line.

\section{Screening and charting the data}

Each of the search strategies was conducted by one of the researchers. Each researcher screened the titles and abstracts to exclude studies that did not meet the inclusion and exclusion criteria. The researchers then sent their selected studies to the principal researcher who excluded duplications and combined the studies into one list. The principal researcher then divided the list equally between the researchers who obtained the full-text articles. Full-text articles that did not meet the inclusion and exclusion criteria were excluded and the researchers then extracted data using a standardised template. The template included the first author, date of publication, country of origin, aim of the publication, study design (if appropriate) and key findings. Each researcher then submitted the templates to the principal researcher who integrated them into one document. 


\section{Data synthesis}

Studies were placed into five categories depending on their focus: historical analysis, model of COPC, implementation of COPC, education and COPC, or effectiveness of COPC. The key characteristics of the studies were entered into an Excel spreadsheet and analysed in terms of year of publication, country of origin, type of publication, type of study design and category. The key findings were then summarised thematically in a narrative. The research team met for a 3-day workshop in Johannesburg to validate the summary of the scoping review. As this is a scoping review, there was no formal review of the quality of the included literature.

\section{Identification of knowledge gaps}

In all, 15 members of the African Primafamed (Primary care and Family Medicine) network (a network of university departments of family medicine and primary care) met in Johannesburg for a 3-day workshop in April 2018. Participants included the authors of this review and members from eight other African countries (Malawi, Lesotho, Namibia, Uganda, Malawi, Zambia, Nigeria and Botswana) and Belgium. The scoping review was presented to the whole group to validate and peer review the process of the review. The knowledge gaps revealed by the review were discussed. Following this a list of possible research questions was brainstormed and ranked in terms of priority using a nominal group technique. The group considered the following issues when prioritising research questions:

- Available knowledge: What is the current level and quality of available knowledge?

- Leverage: What is the potential for improvements in this area to contribute to strengthening PHC performance?

- Magnitude of need: How cross-cutting in this problem across countries?

- Equity: How likely is research in these areas also likely to reduce disparities?

- Innovation: How likely is the research to stimulate innovation in how PHC is strengthened or how known interventions are implemented?

- Can research address the gap?

- Is another group or entity already doing this work?

\section{Patients and public involvement}

This scoping review did not involve any patients or members of the public.

\section{RESULTS}

\section{Description of included studies}

Overall, 1997 publications were identified, screening of the titles and abstracts resulted in 69 publications and screening of the full-text articles left 39 to be included in the review. Figure 1 shows the flow of study selection.

Table 1 presents the characteristics of the included studies. The number of publications increased substantially in the later 5 years $(n=32)$ compared with the

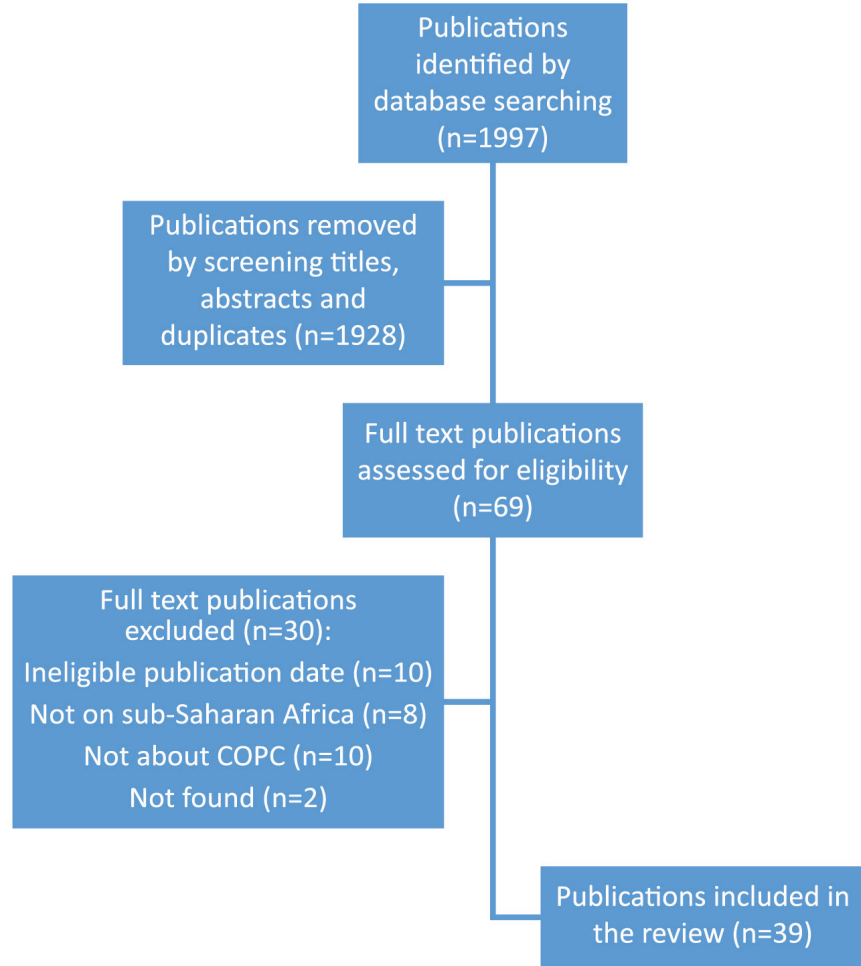

Figure 1 Flow of study selection. COPC, communityorientated primary care.

former $(n=7)$. More than half of the publications originated from South Africa $(n=27)$ while Kenya $(n=4)$, Mozambique $(n=2)$ and Ethiopia $(n=3)$ had more than one each. Most of the publications were research papers $(n=27)$, although almost all were mixed methods (case studies $(n=9)$ and programme evaluations $(n=6))$ or qualitative studies $(n=10)$. Overall, 29 were journal articles, 4 were books or book chapters, 3 were reports published online and 3 were theses published in online repositories. The majority focused on investigating factors that influence the implementation of COPC $(n=25)$, followed by the model of COPC $(n=6)$, history of COPC $(n=4)$, educational studies $(n=3)$ and effectiveness $(n=1)$. There were no articles in French.

\section{Findings related to the history of COPC}

The origins of the COPC model were attributed to Sidney and Emily Kark who pioneered this approach at Pholela in rural South Africa during the 1940s. ${ }^{2}$ 16-18 The Karks transformed the concept of primary care from solo general practitioners offering office-based curative care for individual patients to a personal, family and community-orientated practice. This practice was a multidisciplinary team, based in a health centre, but working extensively within a defined community. The team was also inter-disciplinary and combined health, social and psychological sciences. The team's work was guided by data gathered within the community. Interventions led to significant reductions in syphilis, malnutrition, infant and overall mortality. The advent of Apartheid led to the abandonment of this approach and the emigration of the 


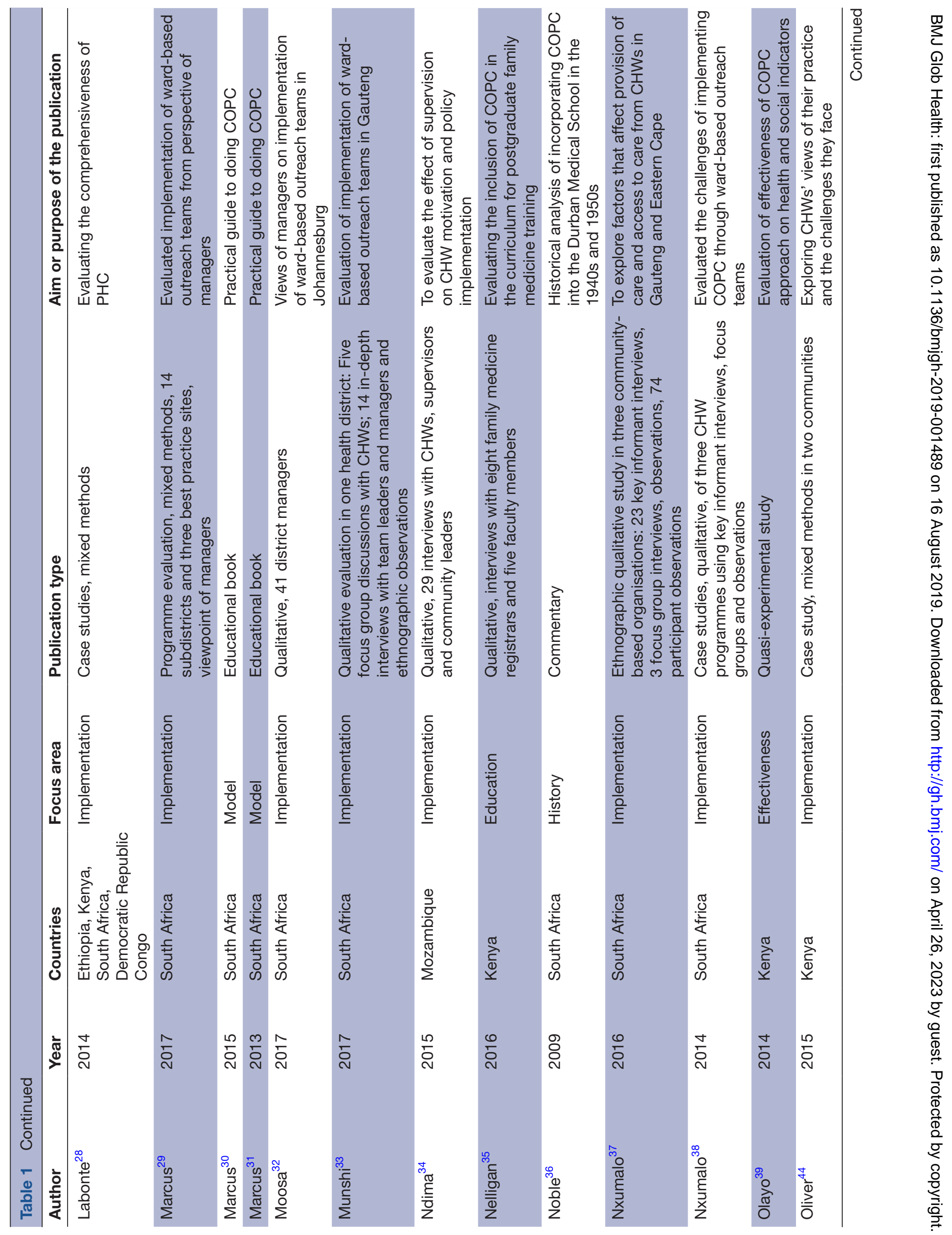




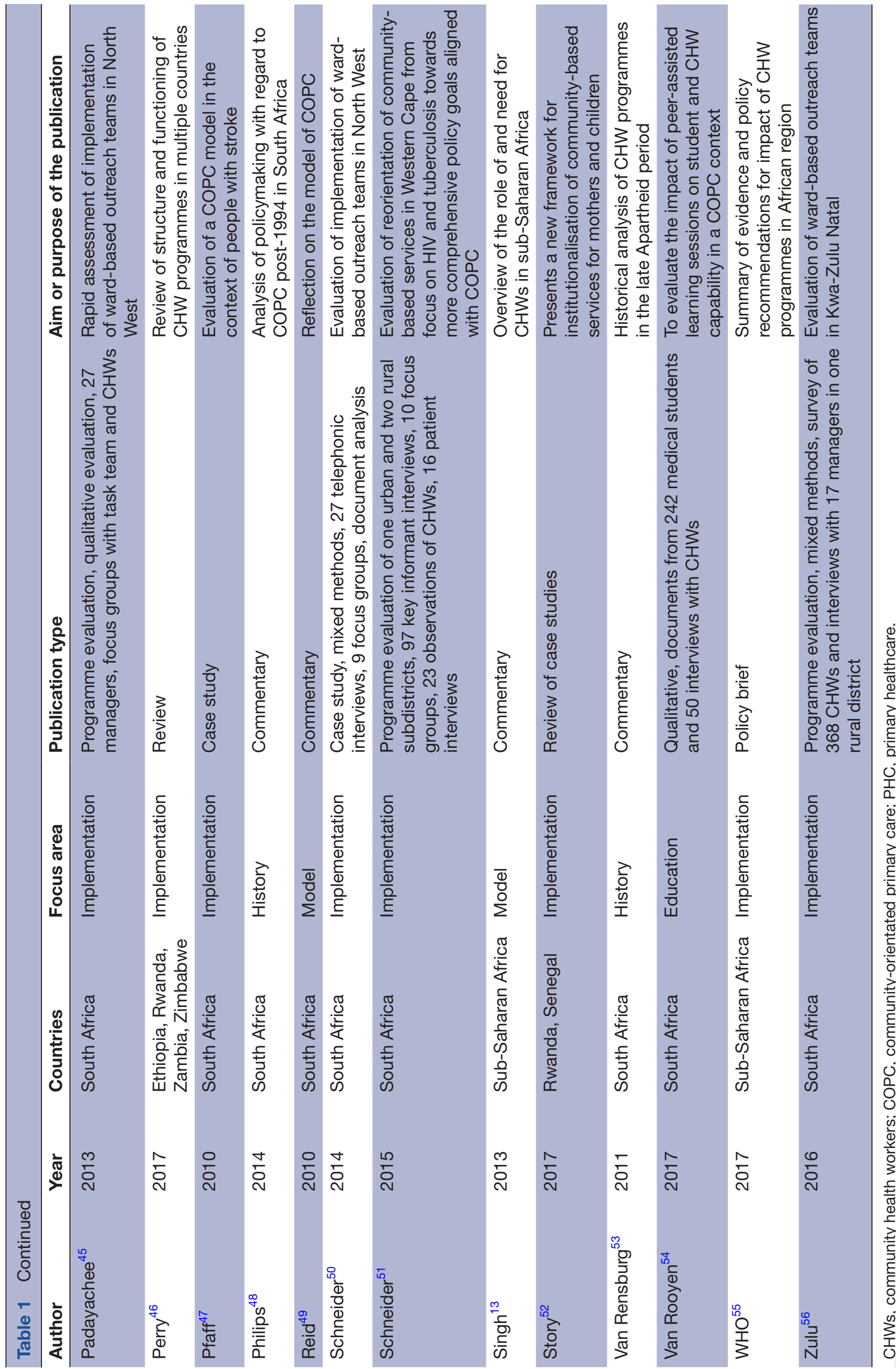


Table 2 Nine key principles of COPC

\begin{tabular}{|c|c|}
\hline Principle & Definition \\
\hline A defined community & The community served is specifically defined, usually in geographical terms \\
\hline $\begin{array}{l}\text { A multidisciplinary team } \\
\text { approach }\end{array}$ & $\begin{array}{l}\text { COPC involves a team of health workers; typically, community health workers, nurses and } \\
\text { sometimes doctors }\end{array}$ \\
\hline A comprehensive approach & $\begin{array}{l}\text { Within the defined community, a COPC approach engages people of all ages, genders and } \\
\text { includes attention to health promotion, disease prevention, care, rehabilitation and palliation }\end{array}$ \\
\hline An equitable approach & $\begin{array}{l}\text { COPC should be accessible, appropriate, affordable and relevant to everyone in the community. } \\
\text { Health equity may be improved }\end{array}$ \\
\hline $\begin{array}{l}\text { Analysis of local health } \\
\text { needs and assets }\end{array}$ & $\begin{array}{l}\text { COPC includes assessment of the health needs of the community as well as the inter-sectoral } \\
\text { resources available to assist with these needs }\end{array}$ \\
\hline $\begin{array}{l}\text { Prioritisation of health needs } \\
\text { and interventions }\end{array}$ & $\begin{array}{l}\text { The analysis of health needs leads to a process of prioritisation and then development of } \\
\text { interventions to address these priorities that involves stakeholders from different sectors }\end{array}$ \\
\hline Community participation & $\begin{array}{l}\text { The analysis of health needs, prioritisation, planning and action should be done in a participatory } \\
\text { approach with community members or structures }\end{array}$ \\
\hline $\begin{array}{l}\text { Evidence-based and } \\
\text { scientific }\end{array}$ & $\begin{array}{l}\text { COPC uses data collected from households, facilities, research and other sources to identify } \\
\text { and respond to individual, household and community health needs }\end{array}$ \\
\hline $\begin{array}{l}\text { Service integration around } \\
\text { users }\end{array}$ & COPC is fundamentally person-centred in how services are coordinated and continuous \\
\hline
\end{tabular}

COPC, community-orientated primary care.

key leaders. While the model is an inspiration, one must also be cautious about transferring ideas from a different social, historical and political context to the current context.

\section{Findings related to the model of COPC}

Nine key COPC principles were identified (table 2). ${ }^{1319-23}$ These principles resonate with the five principles extrapolated from the definition used in the methods, but elaborate further and add important principles such as community participation, being comprehensive and in our context involving a multidisciplinary team. There is no universally accepted definition of COPC, but studies within the African context converged on these nine principles.

A defined community: The community served is usually defined in terms of geographical boundaries and often in terms of a population served by a primary care facility. This goes beyond the practice population to include all members of the population at risk. Household registration can identify the population for which the primary care facility is responsible and potentially be linked to data obtained at the primary care facility on those that have attended. This could meet some of the needs of what the PHCPI refers to as empanelment.

A multidisciplinary team approach: All models of COPC included teams of CHWs supported by a variety of nurses or sometimes doctors. CHWs were typically based in the community and nurses or doctors in the primary care facility. The need for multidisciplinary teams in PHC is also recognised in the PHCPI framework.

A comprehensive approach: COPC should include health promotion, disease prevention, treatment, rehabilitation and palliative care. There was often a particular emphasis in the community on health promotion and disease prevention. Visiting all households systematically was seen as important to promote health and provide health education, identify new cases, trace contacts and support adherence. There was an integration of facility-based and community-based activities within one team. CHWs can often reach marginalised and vulnerable groups within communities.

An equitable approach: COPC should be accessible, appropriate, affordable and relevant to the community. COPC should enable greater health equity.

Analysis of local health needs and assets: COPC includes the gathering of information on health needs of the community as well as institutional or organisational assets within the community that can help to address those needs. Assets may be defined broadly in terms of inter-sectoral actors and not just healthcare.

Prioritisation of health needs and interventions: The analysis of health needs should lead to a process of prioritisation that identifies the most important needs and plans interventions to address the priorities. Interventions should be planned in an inter-disciplinary and inter-sectoral approach. This should enable engagement with the health-related socio-economic and environmental determinants of health.

Community participation: COPC activities, such as the analysis and prioritisation of health needs and planning of interventions, should be done in collaboration with the local community. Appropriate bodies such as community health committees or forums should be established to enable broad collaboration between community members and other role players. The PHCPI framework also included the core element of community engagement as a key feature of effective PHC. Conceptually, 
participation may imply a higher level of collaboration and partnership than just engagement.

Evidence-based and scientific: COPC gathers and analyses quantitative and qualitative data on health from the community and uses this information to plan appropriate responses at the level of the individual, household or community.

Service integration around users: COPC should be person-centred, based on partnerships between people and practitioners and enable continuity of care over time in a continuous process. Person-centredness, coordination and continuity of care are also recognised as key features of quality PHC in the PHCPI framework.

\section{Findings related to implementation of COPC}

\section{Governance}

Implementation of COPC was hindered by a lack of ongoing political commitment, poor cooperation between levels of government and conflicting mandates at the local level. ${ }^{24-26}$

Implementation at a local level may also be constrained by poor inter-sectoral collaboration between government departments. ${ }^{27}$

Managers within the district health system must have a high level of understanding and ownership of COPC. ${ }^{28}$ Risks to implementation include poor communication within the services and a centralised leadership style that does not trust the COPC process. ${ }^{29}$ COPC must be seen in an integrated way with other healthcare reforms.

\section{Financing}

Financial commitment is required to provide sufficient CHWs, ensure supportive supervision, procure essential supplies and equipment, support the data management system, train the people involved, and support operational costs such as space and transport. ${ }^{31}{ }^{31}$ A failure to support one of these essential aspects risks the success of the whole endeavour.

\section{CHW teams}

Approaches based on volunteerism are less likely to succeed than those based on employment. ${ }^{13} 32$ A number of issues impact on retention of CHWs such as low salaries, part-time employment, interruptions in payment, uncertain contractual arrangements, no benefits and a lack of career progression opportunities. ${ }^{24}$ If employment of CHWs is made via a non-government organisation (NGO), then there may be conflict between the goals of the NGO and that of the health services.

Appropriate selection of CHWs is important. ${ }^{24}$ While educational criteria may be important, the CHWs should also be embedded in the community and indigenous culture.

A COPC approach often requires a re-think of the competencies required of CHWs to fulfil more comprehensive roles. CHWs should not continue to be seen as just extending the services of clinics or a particular vertical disease programme. Implementation requires clarity on what the essential competencies are and how these are addressed in training. Existing CHWs must be willing to adapt and integrate the new skills. A balance must be struck between the possible workload and accumulation of different tasks.

CHWs must also balance their ability to act as natural helpers, much like a family member or neighbour who offers simple care that is culturally appropriate, and their new tasks as part of the health system. ${ }^{25}$ CHWs often allow patients to voice their difficulties and barriers to care and have a critical opportunity to assist the patient with these issues, although this may require access to resources and inter-sectoral networks. ${ }^{25}$

The effectiveness of CHWs is often limited by a lack of equipment (eg, uniforms, kit bags, cell phones, medical equipment) or other resources (eg, transport, space to meet, office equipment). ${ }^{28} 33$

A huge factor in successful implementation is the provision of strong management and supportive supervision. ${ }^{31}$ Suboptimal team leadership may be because the person is already fully committed at the local clinic, does not have the capability or training. ${ }^{29}$ Other team members, such as health promoters or environmental health officers, may not be available. A failure to adequately staff the team is a recipe for poor implementation.

Family physician training often includes a role as champion of COPC and they can be a key role player within the sub-district to progressively build the COPC team and functionality.

\section{Primary care facilities}

COPC requires a functional integration of primary care staff in the clinic with those in the community. CHWs need to build good relationships with healthcare workers in the primary care facility. Clinic-based staff may be resistant because they anticipate that COPC will increase their workload or give them additional tasks. ${ }^{24}{ }^{29}$ Primary care providers are typically nurses or mid-level practitioners (eg, clinical officers, physician assistants, clinical associates) supported by doctors. Doctors may be present in larger primary care facilities, visiting from a local hospital or not available. In the short term, COPC may increase service utilisation, although if successful may decrease the disease burden in the longer term.

Clinic-based staff may continue to see the role of the CHW as an extension of the clinic rather than understanding their broader role within the whole community. Requiring CHWs to operate from the facility may waste time in travel and in most cases they should probably operate from locations outside the clinic. ${ }^{28}$

\section{Community participation}

The relationship of CHWs to their community is impacted by their ability to access support and resources, as well as concerns regarding confidentiality and privacy. ${ }^{25}{ }^{29}$ If they are unable to assist community members, then the community loses confidence in them. Tension may also exist between community 
needs or expectations and what CHWs are equipped and authorised to deliver. ${ }^{34}$ A community with strong social cohesion and social capital provides an enabling environment for $\mathrm{CHWs}{ }^{4}$

Active engagement with community members appears essential. Dialogue between community members, local managers, facility staff and CHWs is needed, particularly with regard to health needs, prioritisation and planning of interventions. Community-based health-related activities may require a different set of competencies from primary care workers other than clinical care and have implications for training.

Different communities may have different understandings of participation that range from the sharing of information to involvement in decision-making regarding health services. Health facility community committees can assist with community participation, but may also lead to conflict as community members are more aware of their rights. Community participation can also reflect paternalistic and authoritarian community leadership styles and undermine opportunities for participation from women, youth and marginalised men.

As well as engaging community members a COPC approach must also create a network of other relevant stakeholders. These may be governmental, faith-based, non-governmental, private sector or civil society groups.

\section{Monitoring, evaluation, data and health information}

Evidence is needed to inform planning and monitor implementation of COPC from both the routine health information system, additional audits or reports, staff performance review and supervision. ${ }^{30} 31$

Data collected at the household level or other places by the CHWs need an information system to capture, analyse and convert it into useful information that can be used in decision-making. ${ }^{245}$ The quality of this data should be checked and verified. Cell phone technology and m-health solutions are being piloted to enable CHWs to collect such data. Information should support COPC at the individual, household and community level. Ideally, such data should be integrated with the rest of the PHC information system.

\section{Findings related to effectiveness}

One quasi-experimental study was identified from Kenya that demonstrated significant benefits in terms of antenatal care, health facility delivery, water use, food availability, hand washing, presence of clinic card and measles vaccination. ${ }^{36}$ Impact was greater in rural compared with peri-urban or urban areas.

\section{Findings related to education and training}

Initial training of CHWs needs to be aligned with the more comprehensive roles and competencies of COPC. ${ }^{20}$ Training then needs to be experiential, ongoing and structured into everyday COPC practice. ${ }^{28} 34$ Training should be linked to assessment and career progression. ${ }^{28}{ }^{29}$ In addition to more organised training, supportive supervision is important in building capacity. ${ }^{33}$

Departments of family medicine have embraced the postgraduate training of family physicians in COPC and identified learning outcomes. ${ }^{37}$ Benefits have also been described in undergraduate education by exposing medical students to COPC in longitudinal educational initiatives. ${ }^{38} 39$ Students reported improved personal development, better awareness of the local context, community engagement and responsiveness to community health needs, opportunities for health promotion and community interventions, experience of collaborative teamwork, taking a population perspective and understanding the underlying social determinants of health. CHWs also appeared to benefit from engagement with students and there was improved knowledge sharing with the community. No studies were found looking at education of other healthcare workers.

\section{DISCUSSION}

This review identifies nine key principles of COPC in the sub-Saharan African context, which resonate with principles expressed elsewhere. ${ }^{40}$ These principles also dovetail with the eight key design principles recognised by the CHW impact project for community health systems, although the need to formally accredit CHW competence and to avoid user fees were not seen in the African literature on COPC. ${ }^{38}$ Many health systems use CHWs, but only a few do so in a way that meets these COPC principles, and many use CHWs as part of vertical disease programmes, as extension of services from primary care facilities or for task shifting from other primary care providers. Although the term COPC is gaining acceptance in the PHC literature, in Africa it appears to be unfamiliar outside of South Africa and Kenya, and researchers coming from other disciplines, such as public health, may also not use this term. There may therefore still be a need to identify and describe models of COPC that have been conceptualised and implemented in other countries.

Most of the published work was from South Africa, which may reflect the recent focus on COPC as part of re-engineering PHC. ${ }^{14}$ This policy initiative has led to a number of studies evaluating implementation in the last 5 years. Following the Declaration of Alma-Ata, a number of African countries implemented COPC type initiatives during the 1980s and 1990s, but as this scoping review looked at the last 10 years these studies would not have been included. There is a need for more recent studies on COPC from a wider variety of countries in the region.

Almost all of the research was qualitative or mixed methods in the form of case studies or programme evaluations. There is a need for more observational or experimental research to evaluate the effectiveness of COPC in the sub-Saharan context. There may also be a need to develop tools or extend existing ones, such as the 
Primary Care Assessment Tool, ${ }^{41}$ to allow evaluation of the whole COPC model. There may also be a need to evaluate COPC when implemented at scale in health systems outside of particular cases or projects. South Africa and Kenya may provide an opportunity to do this as COPC is embedded in national policy.

Among the implementation research, there was little exploration of the functional integration of public health and primary care competencies among healthcare workers as well as the implications for training. COPC training may need to be more prominent in nursing and medical education at both undergraduate and postgraduate levels. In South Africa, for example, the need to re-orientate general practitioners at scale to COPC has been identified. ${ }^{42}$ Although the studies highlighted the importance of political commitment, there was little research focusing on how COPC is included in policy. The evidence base on implementation also points to a number of issues that need further evaluation. These include the evaluation of m-health-based information systems, the underlying datasets and their interoperability with other parts of the information system at the facility and higher levels. Further evaluation of different approaches to training, the scope of practice of CHWs in a COPC framework, the approach to supportive supervision and experiential workplace based learning, is needed. Ways of modelling COPC should also be developed and evaluated to assist policymakers in planning human and financial resources at scale. The studies on education appeared to be largely from family medicine and medical education and further evaluation of training on COPC by other disciplines and for other health workers is needed in the African context.

The scoping review was a collaborative activity among four researchers who all reside in different countries. Each person independently and separately conducted one of the subsearches in the protocol. They then applied the agreed definition of COPC to select the included studied and so there is a possibility of selection bias as the selection was not checked by a second independent researcher. Many of the key findings came from more than one study and are unlikely to be substantially altered by this possibility. There could have been some uncertainty with marginal studies as to whether to include or exclude them and reviewers did ask for a second opinion if they were unsure on specific articles. No unpublished or ongoing studies were included. The group did however meet for a 3-day workshop to validate the review results. Many excluded studies evaluated CHWs' ability to perform specific tasks or work for specific health programmes. These studies were not included as we were interested in evaluations of COPC as a whole, in particular its comprehensive nature in delivery of care.

The review led to the identification of five priority research questions:

-What are the current models of COPC in Africa?
- In models of COPC in Africa, is there integration of public health and primary care competencies and what is the skills mix required?

- What is the effectiveness of models of COPC in Africa?

- Is the COPC approach incorporated into the training of healthcare workers in Africa?

- To what extent does national health policy in Africa drive a COPC approach?

Out of these five questions, the review team ranked the question on effectiveness as the most important. Although there is evidence globally for the effectiveness of CHW programmes with specific health programmes, such as maternal and child health, there is a need for more evaluation of the COPC approach as a reform of the PHC system as a whole and within the African context. ${ }^{43}$ This dovetails with previous calls for more research on COPC to evaluate health outcomes and community participation. ${ }^{10}$

\section{CONCLUSIONS}

Over the last 10 years, COPC has been most strongly conceptualised and studied in South Africa, although a number of other countries also had approaches to PHC that met the criteria for COPC. The literature was consistent in identifying nine key principles for COPC in the African context and paid homage to the historical roots of COPC in South Africa during the 1940s. Studies identified numerous strengths and weaknesses in current approaches to COPC that related to governance, financing, CHWs, primary care facilities, community participation, use of data and information, and training. There was little evidence for the effectiveness of COPC in the African context and although such evidence exists internationally, there is a need for more focus on observational and experimental studies within the region.

Acknowledgements The scoping review was briefly outlined in a satellite session at the The Fifth Global Symposium on Health Systems Research from 8 to 12 October, 2018 in Liverpool, UK.

Contributors RM conceptualised the study with input from SR, AE and EB. All authors participated in the searching for and selection of included studies as well as data extraction. RM synthesised the extracted data. All authors analysed the data in a workshop and RM wrote the initial draft, which was further revised by all authors. All authors approved the final manuscript.

Funding The authors have not declared a specific grant for this research from any funding agency in the public, commercial or not-for-profit sectors. Stellenbosch University provided funding for the 3-day workshop and Ariadne Labs provided funding for the publication.

Competing interests None declared.

Patient consent for publication Not required.

Ethics approval As this was a scoping review of published articles no formal ethical approval was required from Stellenbosch University.

Provenance and peer review Not commissioned; externally peer reviewed.

Data availability statement A summary of the included studies and references to them are included in the article.

Open access This is an open access article distributed in accordance with the Creative Commons Attribution Non Commercial (CC BY-NC 4.0) license, which permits others to distribute, remix, adapt, build upon this work non-commercially, 
and license their derivative works on different terms, provided the original work is properly cited, appropriate credit is given, any changes made indicated, and the use is non-commercial. See: http://creativecommons.org/licenses/by-nc/4.0/.

\section{REFERENCES}

1. Alma-Ata Dof. Available: http://www.who.int/publications/almaata declaration en.pdf [Accessed May 27, 2019].

2. Keegan K, Tollman S. A perspective on primary health care in South Africa: Primary health care: in context. in: South African Health review. Cape Town: Health Systems Trust 2008:17-30.

3. Abramson J. Community-oriented primary care-strategy, approaches, and practice:a review. Public Heal Rev 1988;16:35-98.

4. Crisp N, Capacity GH. Global health capacity and workforce development: turning the world upside down. Infect Dis Clin North Am 2011;25:359-67.

5. Mash R, Howe A, Olayemi O, et al. Reflections on family medicine and primary healthcare in sub-Saharan Africa. BMJ Glob Health 2018;3(Suppl 3):e000662.

6. WHO. The World Health report 2008: Primary Health Care - Now more than ever. Geneva: WHO, 2008.

7. Perry HB. An extension of the Alma-Ata vision for primary health care in light of twenty-first century evidence and realities. Gates Open Res 2018;2.

8. World Health Organization. Astana Declaration on primary health care, 2018. Available: https://www.who.int/primary-health/ conference-phc/declaration [Accessed May 27, 2019].

9. Primary health care performance initiative. Available: https://phcp erformanceinitiative.org/ [Accessed May 27, 2019].

10. Gavagan T. A systematic review of COPC: evidence for effectiveness. J Health Care Poor Underserved 2008;19:963-80.

11. Perry H, Robison N, Chavez D, et al. Attaining health for all through community partnerships: principles of the census-based, impactoriented (CBIO) approach to primary health care developed in Bolivia, South America. Soc Sci Med 1999;48:1053-67.

12. Bastos ML, Menzies D, Hone T, et al. The impact of the Brazilian family health strategy on selected primary care sensitive conditions: a systematic review. PLoS One 2017;12:e0182336.

13. Singh $P$, Sachs JD. 1 million community health workers in subSaharan Africa by 2015. The Lancet 2013;382:363-5.

14. Fryatt B, Hunter J, Matsoso MP. Innovations in primary health care: Considerations for National Health Insurance. In: Padarath A, English $\mathrm{R}$, eds. South African Health review 2013/14. health systems trust, 2014: 33-44.

15. Peters MDJ, Godfrey CM, Khalil H, et al. Guidance for conducting systematic scoping reviews. Int J Evid Based Healthc 2015;13:141-6.

16. Noble V. A medical education with a difference: a history of the training of black student doctors in social, preventive and Community-Oriented primary health care at the University of natal medical school, 1940s-1960. South African Historical Journal 2009;61:550-74.

17. Phillips $\mathrm{H}$. The return of the Pholela experiment: medical history and primary health care in post-Apartheid South Africa. Am J Public Health 2014;104:1872-6.

18. van Rensburg DJ, Wouters E, de Wet K. The evolving socio-political context of community health worker programmes in South Africa: implications for historical analysis. Soc Sci Med 2011;72:1021-4.

19. Bam N, Marcus T, Hugo J, et al. Conceptualizing community oriented primary Care (COPC) - the Tshwane, South Africa, health post model. Afr J Prim Health Care Fam Med 2013;5.

20. Marcus T. A practical guide to doing community oriented primary care. Pretoria: Minuteman Press, 2015.

21. Marcus T. Community oriented primary care. Cape Town: Pearson, 2013.

22. Reid S. Community-oriented primary care: the missing link. Afr J Prim Health Care Fam Med 2010;2.

23. World Health Organization. Regional office for Africa. Community health worker programmes in the WHO African region: evidence and options - policy brief. Brazzaville: WHO Africa Region, 2017.

24. Munshi S. Exploring the municipal ward based primary health care outreach teams implementation in the context of primary health care re-engineering in Gauteng, 2017. Available: http://wiredspace.wits. ac.za/handle/10539/23346 [Accessed May 27, 2019].

25. Nxumalo N, Goudge J, Manderson L. Community health workers, recipients' experiences and constraints to care in South Africa - a pathway to trust. AIDS Care 2016;28 Suppl 4:61-71.

26. Story WT, LeBan K, Altobelli LC, et al. Institutionalizing communityfocused maternal, newborn, and child health strategies to strengthen health systems: a new framework for the sustainable development goal era. Global Health 2017;13.

27. Nxumalo NL. Community health workers, community participation and community level inter-sectoral action: the challenges of implementing primary health care outreach services, 2014published online April 25. Available: http://wiredspace.wits.ac.za/handle/ 10539/14597 [Accessed May 27, 2019].

28. Marcus TS, Hugo J, Jinabhai CC. Which primary care model? A qualitative analysis of ward-based outreach teams in South Africa. Afr J Prim Health Care Fam Med 2017;9.

29. Moosa S, Derese A, Peersman W. Insights of health district managers on the implementation of primary health care outreach teams in Johannesburg, South Africa: a descriptive study with focus group discussions. Hum Resour Health 2017;15.

30. Padayachee T, Chetty N, Matse M, et al. Progress in the establishment of ward based outreach teams: experiences in the North West Province. Cape Town: Health Systems Trust, 2013.

31. Zulu MT. An evaluation of the management of rural ward-based primary health care : a case study of Uthukela District Municipality in KwaZulu-Natal, 2016. Available: https://ir.dut.ac.za/handle/10321/ 1558 [Accessed May 27, 2019].

32. Kinkel H-F, Marcus T, Memon S, et al. Community oriented primary care in Tshwane district, South Africa: assessing the first phase of implementation. Afr J Prim Health Care Fam Med 2013;5.

33. Giugliani C, Duncan BB, Harzheim E, et al. Community health workers programme in Luanda, Angola: an evaluation of the implementation process. Hum Resour Health 2014;12.

34. Austin-Evelyn K, Rabkin M, Macheka T, et al. Community health worker perspectives on a new primary health Care initiative in the Eastern Cape of South Africa. PLoS One 2017;12:e0173863.

35. Jinabhai C, Marcus T, Chaponda A. Rapid appraisal of ward based outreach teams. Lynnwood: Minuteman Press, 2015

36. Olayo R, Wafula $\mathrm{C}$, Aseyo $\mathrm{E}$, et al. A quasi-experimental assessment of the effectiveness of the community health strategy on health outcomes in Kenya. BMC Health Serv Res 2014;14 Supp

37. Nelligan IJ, Shabani J, Taché S, et al. An assessment of implementation of CommunityOriented primary care in Kenyan family medicine postgraduate medical education programmes. Afr $J$ Prim Health Care Fam Med 2016;8.

38. E Knight S, J Ross A, Mahomed O. Developing primary health care and public health competencies in undergraduate medical students. South African Family Practice 2017;59:103-9.

39. van RM, Reinbrech-Schütte A, Hugo JFM, et al. Developing capability through peer-assisted learning activities among 4th-year medical students and community health workers in community settings. African J Heal Prof Educ 2017;9:73-7.

40. Mpofu E. Community-Oriented health services: practices across disciplines. New York: Springer, 2015.

41. Bresick G, Sayed A-R, Le Grange C, et al. Adaptation and crosscultural validationof the United States primary Care assessment tool (expanded version) for use in South Africa. Afr J Prim Health Care Fam Med 2015;7:1-11.

42. Moosa S, Peersman W, Derese A, et al. Emerging role of family medicine in South Africa. BMJ Glob Health 2018;3(Suppl 3):e000736.

43. Black RE, Taylor CE, Arole S, et al. Comprehensive review of the evidence regarding the effectiveness of community-based primary health care in improving maternal, neonatal and child health: 8. summary and recommendations of the expert panel. $J$ Glob Health 2017;7.

44. Aantjes C, Quinlan T, Bunders J. Integration of community home based care programmes within national Primary health care revitalisation strategies in Ethiopia, Malawi, South-Africa and Zambia: a comparative assessment. Global Health 2014;10.

45. Adie $\mathrm{H}$, Igbang $\mathrm{T}$, Otu $\mathrm{A}$, et al. Strengthening primary healthcare through community involvement in Cross River state, Nigeria: a descriptive study. Pan Afr Med J 2014;17.

46. Baatiema L, Skovdal M, Rifkin S, et al. Assessing participation in a community-based health planning and services programme in Ghana. BMC Health Serv Res 2013;13.

47. Curry LA, Alpern R, Webster TR, et al. Community perspectives on roles and responsibilities for strengthening primary health care in rural Ethiopia. Glob Public Health 2012;7:961-73.

48. De Neve J-W, Garrison-Desany H, Andrews KG, et al. Harmonization of community health worker programs for HIV: a four-country qualitative study in southern Africa. PLoS Med 2017:14:e1002374 
49. Dookie S, Singh S. Primary health services at district level in South Africa: a critique of the primary health care approach. BMC Fam Pract 2012;13.

50. Labonté R, Sanders D, Packer C, et al. Is the Alma Ata vision of comprehensive primary health care viable? Findings from an international project. Glob Health Action 2014;7.

51. Ndima SD, Sidat M, Give C, et al. Supervision of community health workers in Mozambique: a qualitative study of factors influencing motivation and programme implementation. Hum Resour Health 2015;13.

52. Oliver M, Geniets A, Winters N, et al. What do community health workers have to say about their work, and how can this inform improved programme design? A case study with $\mathrm{CHWs}$ within Kenya. Glob Health Action 2015;8.
53. Perry $\mathrm{H}$, Crigler $\mathrm{L}$, Lewin $\mathrm{S}$, et al. A new resource for developing and strengthening large-scale community health worker programs. Hum Resour Health 2017;15.

54. Pfaff C, Tollman S, Kahn K. Developing Community-Oriented Primary Care (COPC) in Contemporary Rural South Africa: The Case of Stroke. In: Gofin J, Gofin R, eds. Essentials of Global Community Health. Jones \& Bartlett, 2010: 151-6.

55. Schneider $\mathrm{H}$, English $\mathrm{R}$, Tabana $\mathrm{H}$, et al. Whole-system change: case study of factors facilitating early implementation of a primary health care reform in a South African Province. BMC Health Serv Res $2014 ; 14$.

56. Schneider H, Schaay N, Dudley L, et al. The challenges of reshaping disease specific and care oriented community based services towards comprehensive goals: a situation appraisal in the Western Cape Province, South Africa. BMC Health Serv Res 2015;15. 